\title{
Biodegradação de Filmes de Polipropileno (PP), Poli(3-hidroxibutirato) (PHB) e Blenda de PP/PHB por Microrganismos das Águas do Rio Atibaia
}

\author{
Adriano Uemura de Faria, Sandra Mara Martins-Franchetti \\ Departamento de Bioquímica e Microbiologia do Instituto de Biociências, UNESP
}

\begin{abstract}
Resumo: O propósito deste estudo é investigar a biodegradação de filmes de PHB, PP e blenda de PP/PHB (1:1) por microrganismos de águas de rio poluído que recebeu vários tipos de descartes, inclusive de refinaria de petróleo. Os filmes poliméricos foram obtidos por fusão do pó do material a $175{ }^{\circ} \mathrm{C}$, prensados a $71,3 \mathrm{kgf} . \mathrm{cm}^{-2}$ e resfriados a $25{ }^{\circ} \mathrm{C}$. Estes filmes foram mantidos em amostras de águas do rio poluído, coletadas antes e após o descarte do efluente da refinaria de petróleo e mantidas em estufa bacteriológica a $28{ }^{\circ} \mathrm{C}$, durante 120 dias. As mudanças, causadas pela ação microbiana nos filmes, foram analisadas por medidas de perda de massa, infravermelho com transformada de Fourier (FTIR) e microscopia eletrônica de varredura (MEV). Os resultados provaram que a degradação do PHB ocorre tanto na sua fase amorfa como na cristalina, sendo mais significativa na água do rio que recebeu o efluente da refinaria de petróleo, contendo microrganismos reconhecidos como potencialmente capazes de degradar substâncias persistentes no meio ambiente.
\end{abstract}

Palavras-chave: Biodegradação, PP, PHB, blendas, microrganismos, rio poluído.

\section{Biodegradation of Polypropylene (PP), Poly(3-hydroxybutyrate) (PHB) Films and PP/PHB Blend by Microorganisms from Atibaia River}

\begin{abstract}
The purpose of this study is to investigate the biodegradation of films made with PP, PHB and PP/PHB (1:1) blend caused by microorganisms from polluted river which received several types of waste, including an oil refinery effluent. The films were obtained by melting the powder from the material at $175^{\circ} \mathrm{C}$, pressed at $71.3 \mathrm{kgf.cm}{ }^{-2}$ and cooled at $25^{\circ} \mathrm{C}$. These films were kept in polluted river water samples, collected before and after the discarding of oil refinery waste, and they were kept in the bacteriological incubator at $28{ }^{\circ} \mathrm{C}$ for 120 days. The changes caused by microbial action on the films were analyzed by measurements of weight loss, Fourier transform infrared (FTIR) and scanning electronic microscopy (SEM). The results proved that PHB degradation occurs in amorphous and crystalline phases, being more significant in the river water which received refinery oil waste, containing microorganisms recognized as potentially capable to degrade recalcitrant substances in the environment.
\end{abstract}

Keywords: Biodegradation, $P$ P, PHB, blends, microorganisms, polluted river.

\section{Introdução}

Os polímeros sintéticos tornaram-se importantes na sociedade porque podem substituir materiais como: papel, madeira, vidro e metal, solucionando grande número de problemas, quer na indústria, na agricultura, na medicina e em outras áreas. Isso se deve às características como: durabilidade, atoxicidade, baixo custo, facilidade para serem moldados, capacidade de serem reciclados e versatilidade de aplicação. $\mathrm{O}$ mercado de resinas plásticas tem aumentado ultimamente, significando uma expansão da indústria petroquímica, que movimenta a economia e gera empregos em diversos segmentos do setor ${ }^{[1,2]}$. Entretanto, o uso e o descarte indevidos dos materiais plásticos, aliados a sua resistência à degradação acabam gerando problemas ambientais sérios. Para minimizar o problema de acúmulo de resíduos plásticos, algumas alternativas têm sido propostas, tais como: diminuição do consumo e reciclagem do material, aterramento e incineração dos resíduos. A substituição de parte dos polímeros sintéticos por polímeros biodegradáveis constitui uma alternativa viável, uma vez que existe a possibilidade de misturar polímeros de naturezas diferentes, na forma de blendas, garantindo a sua aplicabilidade e, com isso, melhorar a biodegradabilidade do material resultante $\mathrm{e}^{[1-4]}$.

O poli(3-hidroxibutirato) (PHB)é um biopolímero obtido de fontes renováveis, suas propriedades se assemelham às do polipropileno que é um polímero sintético de grande consumo $^{[5,6]}$, a aplicação de ambos os polímeros na forma de blenda poderia favorecer a degradação da mesma. Entretanto, para determinadas aplicações, não é interessante que sua degradação seja muito rápida, o que poderia ser modulada pela presença do polipropileno (PP), polímero sintético e não biodegradável ${ }^{[6]}$. 
A biodegradação, protagonizada por microrganismos capazes de produzir enzimas que hidrolisam os polímeros, também constitui uma alternativa para o tratamento dos resíduos plásticos. Estes microrganismos estão distribuídos nos ecossistemas e são responsáveis pela manutenção dos ciclos biogeoquímicos, uma vez que degradam a matéria orgânica ${ }^{[5,7]}$. Águas poluídas por hidrocarbonetos podem constituir um ambiente propício à presença de microrganismos potencialmente degradadores de uma variedade de moléculas recalcitrantes lançadas no meio, inclusive de polímeros. A prospecção de microrganismos que resultem em algum interesse e/ou aplicabilidade na biodegradação de polímeros pode ser mais sucedida em ambientes nos quais os microrganismos já estão, de certa forma, adaptados com a presença de moléculas recalcitrantes no meio. Neste sentido o Rio Atibaia é um ambiente propício à prospecção de microrganismos potencialmente biodegradadores de macromoléculas. Este rio está localizado na bacia hidrográfica do Rio Piracicaba, possui cerca de $182 \mathrm{~km}$ de extensão e recebe o descarte de efluente de refinaria de petróleo ${ }^{[8]}$.

A biodegradação de superfícies poliméricas é resultado das interações interfaciais com os microrganismos e depende de fatores como hidrofobicidade, umidade e nutrientes, para que ocorra a adesão de microrganismos, colonização e formação de biofilme sobre o material ${ }^{[9]}$.

Vários estudos de biodegradação do PHB verificaram que sua taxa de degradação é inversamente relacionada ao seu grau de cristalinidade, pois as enzimas microbianas degradam mais a fase amorfa do polímero ${ }^{[5,10]}$. Entretanto, há estudos com enzimas de Pseudomonas lemoignei que evidenciam a degradação indiscriminada de ambas as fases, amorfa e cristalina, neste caso o ataque enzimático ocorreria tanto no material amorfo interlamelar como nas lamelas cristalinas do $\mathrm{PHB}^{[10]}$.

Estudos realizados com fitas de poliolefinas de $1,5 \mathrm{~mm}$ de espessura, incubadas em ambiente aquático marinho, mostraram que estas amostras sofreram degradação em seis meses sob condições de ambiente tropical, como alta temperatura, alto nível de oxigênio dissolvido e presença de microrganismos ${ }^{[11]}$.

O objetivo deste trabalho foi verificar a capacidade de degradação de polímeros por microrganismos presentes na água do Rio Atibaia, para isso, comparou-se a biodegradação de filmes de poli(3-hidroxibutirato), polipropileno e blenda de PP/PHB (1:1) em dois meios de biotratamento: a) água do Rio Atibaia antes do descarte do efluente da refinaria de petróleo e b) água do Rio Atibaia após o descarte do efluente, uma vez que a carga microbiana é diferente nestes dois meios.

\section{Experimental}

\section{Materiais}

\section{Polímeros}

Os polímeros utilizados foram:

- Polipropileno (PP), Suzano Petroquímica S.A., TS-6.100, Mळ 145.000 g.mol ${ }^{-1}$;

- Poli(3-hidroxibutirato) (PHB), Mळ 603.810 g.mol ${ }^{-1}$, doação do Departamento de Engenharia de Materiais da Universidade Federal de São Carlos, SP.

\section{Fonte dos microrganismos}

- Os microrganismos envolvidos nos ensaios de biodegradação foram os autóctones presentes nas águas do Rio Atibaia.

\section{Meios de cultivo}

- Meio de cultura plate count agar (PCA) para plaqueamento e contagem de microrganismos. Composição $(\mathrm{m} / \mathrm{v}): 0,5 \%$ peptona; $0,25 \%$ extrato de levedura; $0,1 \%$ glicose; $1,5 \%$ ágar; água destilada; $\mathrm{pH} 7,0( \pm 0,2)$ a $25^{\circ} \mathrm{C}^{[12]}$.

- Meio de cultura "ágar nutriente" (AN) para isolamento de bactérias. Composição (m/v): 0,3\% extrato de carne; $0,5 \%$ peptona; $1,5 \%$ ágar; água destilada; $\mathrm{pH} 6,8$ $( \pm 0,2)$ a $25^{\circ} \mathrm{C}^{[12]}$.

\section{Meios de biotratamento}

- Os meios de biotratamento foram água do Rio Atibaia coletada à montante e jusante, ou seja, antes e depois do descarte do efluente industrial de refinaria de petróleo.

\section{Métodos}

\section{Preparo dos filmes e blendas}

Filmes de $70 \mu \mathrm{m}$ de espessura foram obtidos por fusão dos polímeros em prensa aquecida sob temperatura de $175^{\circ} \mathrm{C}$ e 71,3 kgf. $\mathrm{cm}^{-2}$ de pressão por 2 minutos e resfriados em temperatura ambiente de 25 a $26^{\circ} \mathrm{C}$. Nos filmes de PP e PHB foram utilizados $0,2 \mathrm{~g}$ de cada polímero em pó. Os filmes da blenda (50 de PP e 50\% de PHB) foram obtidos utilizando-se $0,1 \mathrm{~g}$ de cada homopolímero.

\section{Ensaios de biodegradação}

Os filmes de PP, PHB e blenda foram mantidos em frascos contendo água do Rio Atibaia coletada antes do descarte e após o descarte do efluente em incubadora a $28{ }^{\circ} \mathrm{C}$. Como controle foram mantidos os mesmos tipos de filmes em frascos contendo água autoclavada do rio, afim de verificar a possibilidade de hidrólise na ausência de microrganismos. 


\section{Contagem microbiana}

Para monitorar quantidade de microrganismos presentes na água do rio no início e no fim do tratamento dos filmes, utilizou-se a técnica do número mais provável ${ }^{[7]}$, com um plaqueamento inicial e outro final, após os 120 dias, em meio PCA pelo método pour plate. As contagens foram expressas em unidades formadoras de colônias (UFC).

\section{Medidas de massa}

As massas dos filmes, antes e após o biotratamento, foram obtidas em balança analítica da marca CHYO modelo JK $200( \pm 0,0001 \mathrm{~g})$.

\section{Espectroscopia de absorção no infravermelho (FTIR)}

Os filmes originais e biotratados foram analisados por FTIR, em espectrofotômetro IR com transformada de Fourier, marca Shimadzu, modelo FTIR - 8300, com resolução $4 \mathrm{~cm}^{-1}$. Aos espectros obtidos foi aplicado um tratamento matemático (desconvolução) para melhorar a resolução das

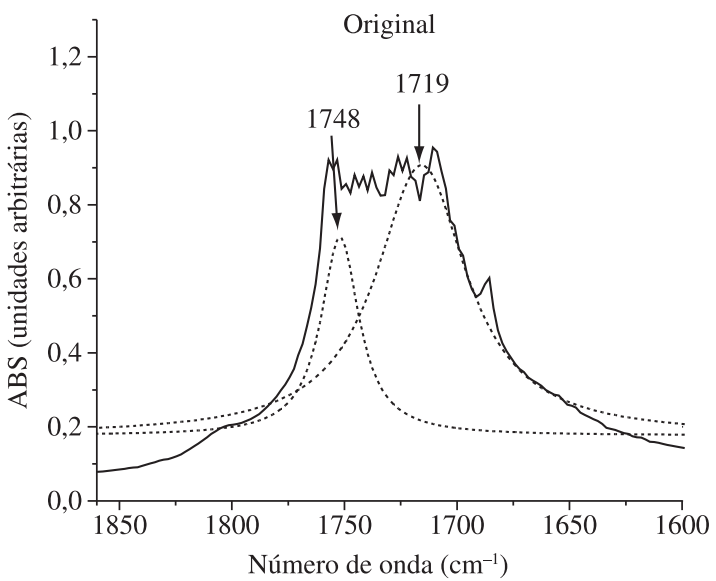

(a)

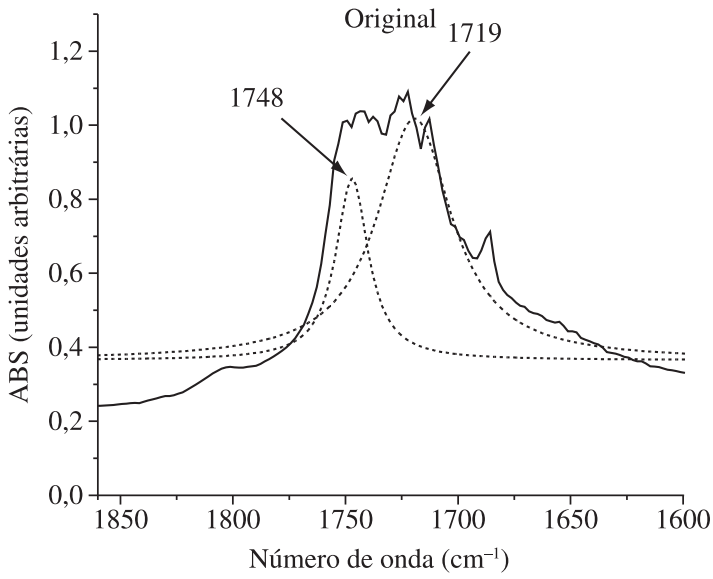

(c) bandas (Software: Origin 8.0, função Lorentziana, aplicada às bandas de carbonila na faixa de 1800 a $1600 \mathrm{~cm}^{-1}$, desconvoluídas para 2 bandas).

Tabela 1. Contagem microbiana em unidades formadoras de colônias por $\mathrm{mL}$ de água do Rio Atibaia antes e após o descarte do efluente.

\begin{tabular}{lccccc}
\hline & \multicolumn{4}{c}{$\mathrm{UFC}_{\mathbf{m} \mathbf{m L}^{\mathbf{- 1}}}$} \\
\cline { 2 - 3 } & \multicolumn{2}{c}{ Antes do descarte } & & \multicolumn{2}{c}{ Após o descarte } \\
\cline { 2 - 3 } \cline { 5 - 6 } & inicial & $\mathbf{1 2 0}$ dias & & inicial & $\mathbf{1 2 0}$ dias \\
\hline PHB & $10^{5}$ & $10^{4}$ & & $10^{6}$ & $10^{5}$ \\
PP & $10^{5}$ & $10^{2}$ & & $10^{6}$ & $10^{2}$ \\
Blenda & $10^{5}$ & $10^{3}$ & & $10^{6}$ & $10^{3}$ \\
\hline
\end{tabular}

Tabela 2. Valores percentuais de perda de massa dos filmes de PHB, PP e blenda de PP/PHB submetidos ao biotratamento em água do Rio Atibaia antes e após o descarte de efluente.

\begin{tabular}{lccc}
\hline & \multicolumn{3}{c}{ Perda de massa (\%) } \\
\cline { 2 - 4 } & Controle & Antes do descarte & Após o descarte \\
\hline PHB & - & $55 \pm 1$ & $66 \pm 1$ \\
Blenda & - & $25 \pm 1$ & $26 \pm 1$ \\
PP & - & - & - \\
\hline
\end{tabular}

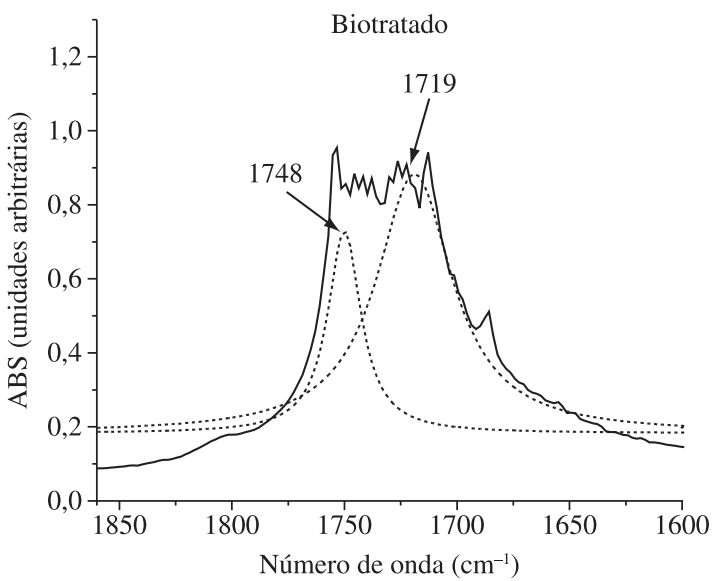

(b)

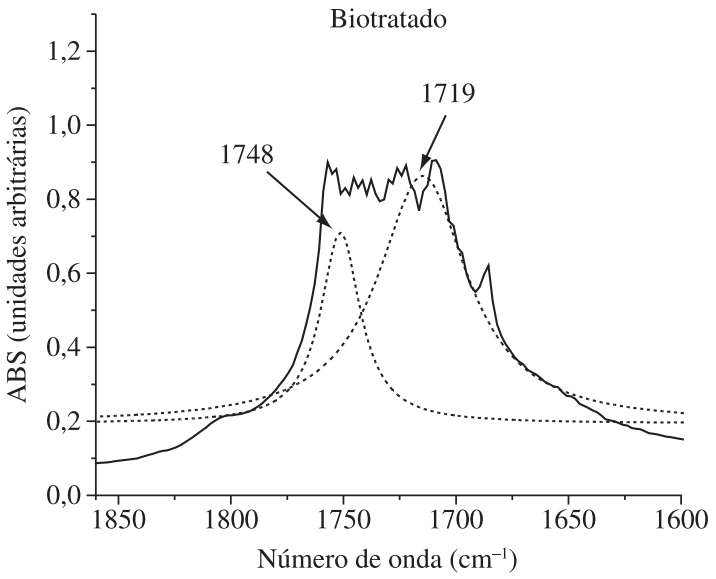

(d)

\section{….. Desconvolução}

Figura 1. Espectros de FTIR, na faixa de $1860-1600 \mathrm{~cm}^{-1}$, com ajuste Lorentziano de filmes de PHB original (a) e biotratado (b), em água do Rio Atibaia antes do descarte e original (c) e biotratado (d) após o descarte do efluente. Obs.: absorbância em $1380 \mathrm{~cm}^{-1}$ como padrão interno. 


\section{Microscopia óptica (MO)}

Os filmes originais e biotratados foram analisados em microscópio óptico, marca BEL ${ }^{\circledR}$ photonics, B4, optech: optical technology Germany.

\section{Microscopia eletrônica de varredura (MEV)}

Os filmes originais e biotratados foram analisados em microscópio eletrônico de varredura (MEV) Zeiss DSM 940-A, a 3 KV (Núcleo de Apoio à Pesquisa em Microscopia Eletrônica Aplicada à Agricultura/Esalq/USP, Piracicaba, SP).

\section{Resultado e Discussão}

Os resultados foram discutidos em relação à contagem microbiana, variação de massa, medidas de FTIR e MEV dos filmes.

Pelos valores obtidos da contagem microbiana em unidades formadoras de colônias (UFC) (Tabela 1), verificou-se que após os 120 dias de biotratamento nos meios em que havia filme de PHB a população microbiana manteve-se maior do que nos demais, evidenciando que o PHB serviu de fonte de carbono para o desenvolvimento microbiano ${ }^{[13]}$. Nos meios em que havia a blenda (com 50\% de PHB), a contagem microbiana foi intermediária e nos meios contendo filme de PP, a contagem foi menor. A hidrofobicidade do PP dificulta a interação com as enzimas limitando a biodegradação ${ }^{[6]} \mathrm{e}$ impedindo a utilização do polímero como fonte de carbono pelos microrganismos.

A determinação da perda de massa é um método comumente aplicado e relativamente sensível para determinar mudanças causadas pelo ataque microbiano nos polímeros ${ }^{[9]}$. Como apresentado na Tabela 2, o PHB sofreu a maior perda de massa quando biotratado em água do rio que recebeu o efluente, evidenciando que este meio foi mais ativo na biodegradação. As perdas de massas das blendas foram próximas, tanto para o tratamento em água antes como após o descarte do efluente e, provavelmente, se deve à degradação do PHB presente na blenda. Em relação o PP não houve variação de massa significativa. Estes resultados concordam com Arcana et al..$^{[6]}$, que realizaram experimentos com PHB e blendas de PP/PHB utilizando microrganismos de lodo ativado, observando que a biodegradação em blendas é menor do que no homopolímero (PHB) e que a biodegradabilidade tende a aumentar lentamente com o aumento da fração de PHB contida na blenda.

Estes resultados mostraram que não houve hidrólise química das amostras (no controle não houve alteração).

As medidas de FTIR analisaram os filmes originais em comparação com os biotratados. Os espectros de PHB (Figura 1 e 2) e blenda (Figura 3) foram normalizados pela intensidade de absorbância de uma banda considerada como padrão interno em $1380 \mathrm{~cm}^{-1}$, atribuída à deformação simétrica de grupos $\mathrm{CH}_{3}{ }^{[14,15,16]}$, e desconvoluídos pela função Lorentziana para obter melhor resolução das bandas (separação em picos) ${ }^{[17]}$.
A Tabela 3 compara os índices carbonila de fase amorfa $\left(1748 \mathrm{~cm}^{-1}\right)$ e de fase cristalina $\left(1719 \mathrm{~cm}^{-1}\right)^{[15,16]}$ dos filmes de PHB e da blenda de PP/PHB originais e biotratados em água do Rio Atibaia antes e após o descarte do efluente (valores extraídos das Figura 1c, d). Na Tabela 4 estão apresentados os índices de fase amorfa e cristalina do PHB, obtidos, respectivamente, dos valores de absorbância da banda em $1186 \mathrm{~cm}^{-1}$ atribuída ao estiramento simétrico de grupo C-O-C e da banda em $1230 \mathrm{~cm}^{-1}$ atribuída à conformação helicoidal de cadeia, em relação à banda de referência em $1380 \mathrm{~cm}^{-1}$, mantida como padrão interno ${ }^{[14,16]}$.

Em relação aos filmes de PHB submetidos ao biotratamento em água do Rio Atibaia antes e após o descarte do efluente, a variação nos índices de carbonila amorfa e cristalina não foram significativas. Entretanto houve perda de massa, sugerindo que a degradação ocorre em ambas as fases, amorfa e cristalina. Quando se comparam os índices de fase amorfa e cristalina obtidos das bandas em $1186 \mathrm{e} \mathrm{em} 1230 \mathrm{~cm}^{-1}$, respectivamente, observa-se que para o biotratamento dos filmes de PHB em água do Rio Atibaia antes do descarte do efluente não houve diferença significativa entre os índices, confirmando a degradação proporcional das fases amorfa e cristalina.

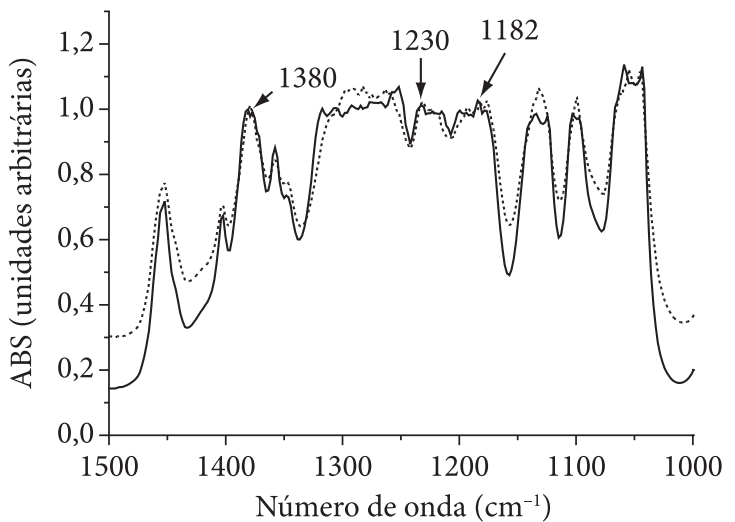

(a)

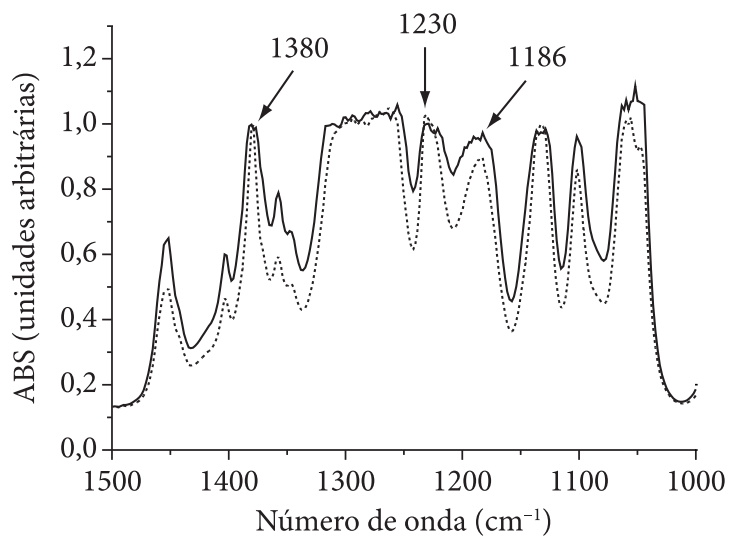

(b)

Figura 2. Espectros de FTIR de filmes de PHB original e biotratado, na faixa de 1500 - $1000 \mathrm{~cm}^{-1}$, em água do Rio Atibaia, a) antes do descarte e b) após o descarte do efluente. Obs.: absorbância em $1380 \mathrm{~cm}^{-1}$ como padrão interno. 


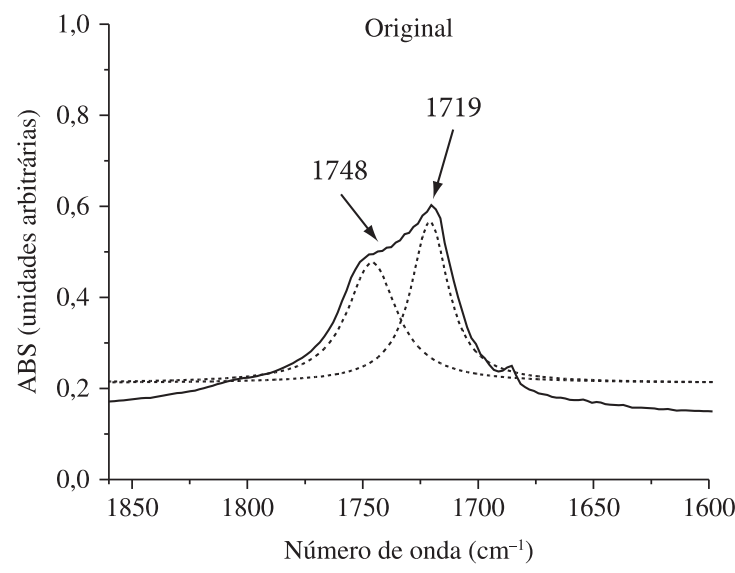

(a)

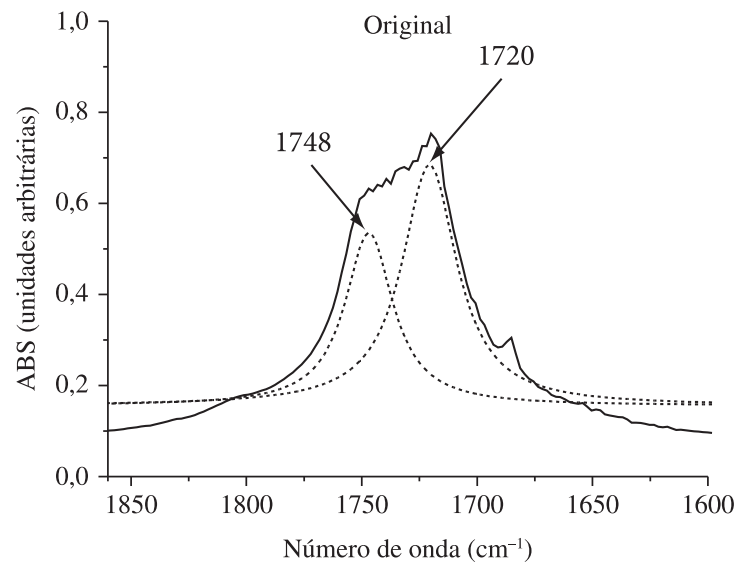

(c)

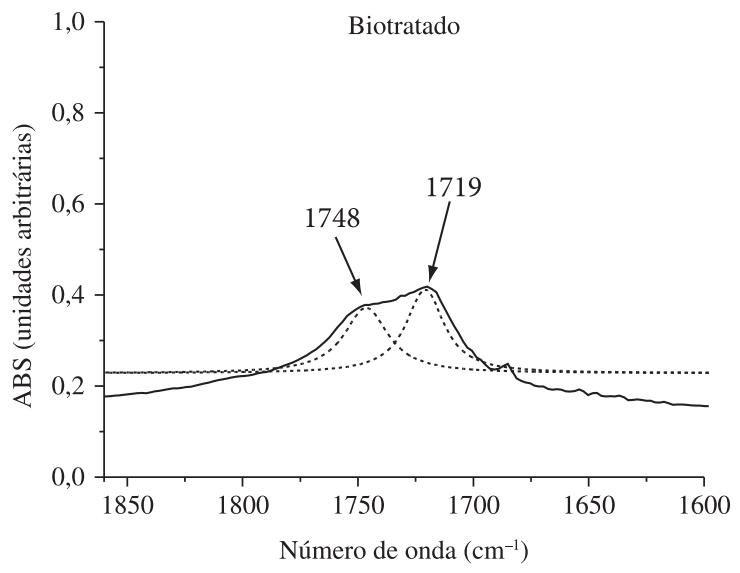

(b)

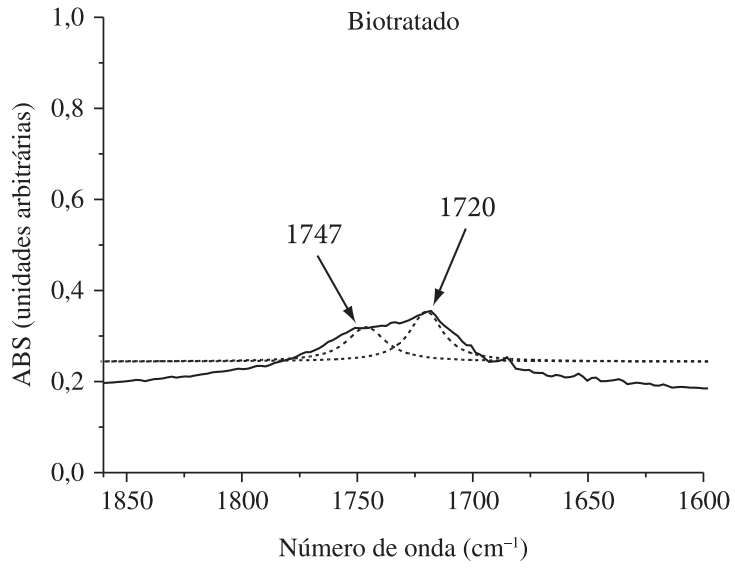

(d)

\section{...... Desconvolução}

Figura 3. Espectros de FTIR, na faixa de 1860 - $1600 \mathrm{~cm}^{-1}$, com ajuste Lorentziano de filmes de blenda de PP/PHB original (a) e biotratado (b), em água do Rio Atibaia antes do descarte e original (c) e biotratado (d) após o descarte do efluente. Obs.: absorbância em $1380 \mathrm{~cm}^{-1}$ como padrão interno.

Tabela 3. Índices de Carbonila de fase amorfa e cristalina calculados para filmes de PHB e blendas de PP/PHB originais e biotratados em água do Rio Atibaia antes e após o descarte do efluente.

\begin{tabular}{|c|c|c|c|c|c|}
\hline & & \multicolumn{4}{|c|}{ Índices de carbonila } \\
\hline & & \multicolumn{2}{|c|}{$\begin{array}{c}\text { Antes do descarte } \\
\text { (Figura 1a, b) }\end{array}$} & \multicolumn{2}{|c|}{$\begin{array}{l}\text { Após o descarte } \\
\text { (Figura 1c, d) }\end{array}$} \\
\hline & & Original & Biotratado & Original & Biotratado \\
\hline Fase amorfa & PHB & 0,54 & 0,53 & 0,51 & 0,49 \\
\hline$\left(\mathrm{ABS}_{1748 / 1380}\right)$ & Blenda & 0,29 & 0,14 & 0,38 & 0,08 \\
\hline Fase cristalina & PHB & 0,73 & 0,70 & 0,67 & 0,65 \\
\hline$\left(\mathrm{ABS}_{1719 / 1380}\right)$ & Blenda & 0,39 & 0,19 & 0,54 & 0,12 \\
\hline
\end{tabular}

Obs.: Desvio padrão de $\pm 0,06$.

A blenda biotratada em água do Rio Atibaia antes do descarte do efluente apresentou diminuição, em torno de $52 \%$, nos índices de carbonilas, tanto na fase amorfa como na cristalina. Na blenda biotratada, após o descarte do efluente, a diminuição de intensidade das bandas refletida nos índices de carbonila tanto da fase amorfa como da cristalina foi, cerca de, $78 \%$, portanto maior que na água do rio antes do descarte do efluente, evidenciando o efeito da microbiota presente.
Sendo assim, é possível inferir que houve biodegradação da fração de PHB presente na blenda, uma vez que o sítio de ataque da enzima PHB-despolimerase é o carbono da carbonila da ligação éster.

Estudos revelaram que a degradação do PHB é seguida de aumento de cristalinidade do polímero ${ }^{[5,10]}$. Entretanto, neste trabalho, verificou-se que houve diminuição proporcional de fase amorfa e cristalina para a fração de PHB da blenda de PHB/PP. 
Tabela 4. Índices de fase amorfa e cristalina de filmes de PHB original e biotratado em água do Rio Atibaia antes e após o descarte do efluente.

\begin{tabular}{lccccc}
\hline & \multicolumn{2}{c}{$\begin{array}{c}\text { Antes de descarte } \\
\text { (Figura 3a-b) }\end{array}$} & & \multicolumn{2}{c}{$\begin{array}{c}\text { Após o descarte } \\
\text { (Figura 3c-d) }\end{array}$} \\
\cline { 2 - 3 } \cline { 5 - 6 } & Original & Biotratado & & Original & Biotratado \\
\hline $\begin{array}{l}\text { Fase amorfa } \\
\left(\mathrm{ABS}_{1186 / 1380}\right)\end{array}$ & 0,54 & 0,53 & & 0,96 & 0,89 \\
$\begin{array}{l}\text { Fase cristalina } \\
\left(\mathrm{ABS}_{1230 / 1380}\right)\end{array}$ & 0,73 & 0,70 & & 1,00 & 1,03 \\
\hline
\end{tabular}

Obs.: Desvio padrão de $\pm 0,06$.

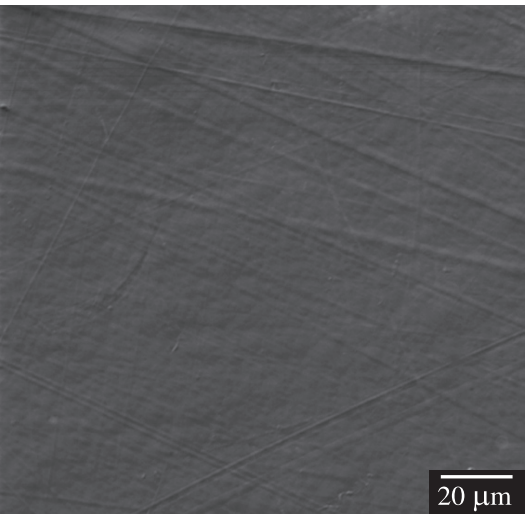

(a)

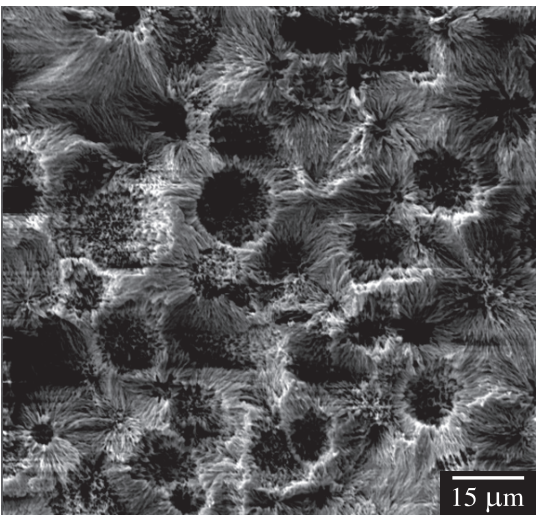

(b)
Segundo Spyros et al. ${ }^{[10]}$ a degradação de filmes de PHB por Pseudomonas lemoignei, em meio líquido pela enzima PHB-despolimerase B, ocorre através da ação enzimática sobre as duas fases, amorfa e cristalina. Inicialmente há ataque na fase amorfa, seguido da fase interlamelar (amorfa) e depois, da fase cristalina. Assim, as razões das frações amorfa e cristalina se mantêm constantes.

Os filmes de PP não sofreram mudanças quando analisados por FTIR. Segundo Arcana et al. ${ }^{[6]}$, o PP é um polímero que

Figura 4. MEV de filmes de PHB: a) filme original; b) biotratado em água do Rio Atibaia antes do descarte do efluente; c) biotratado em água do Rio Atibaia após o descarte do efluente.

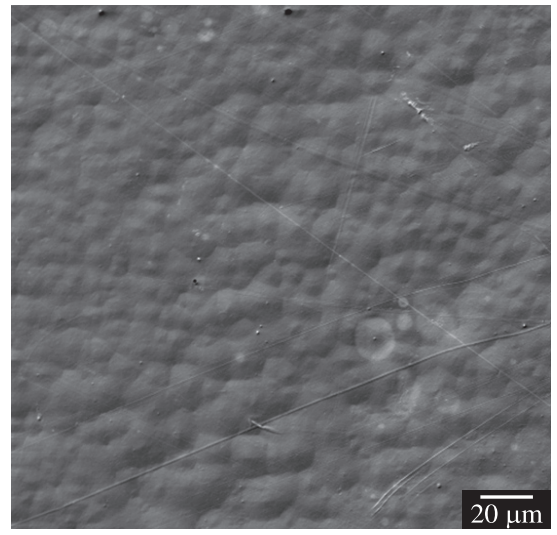

(a)

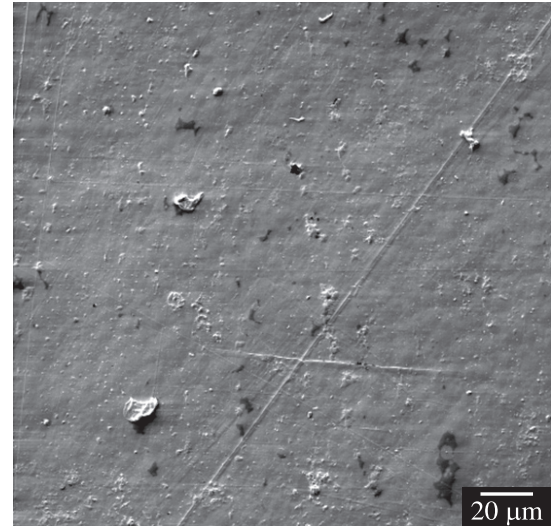

(b)

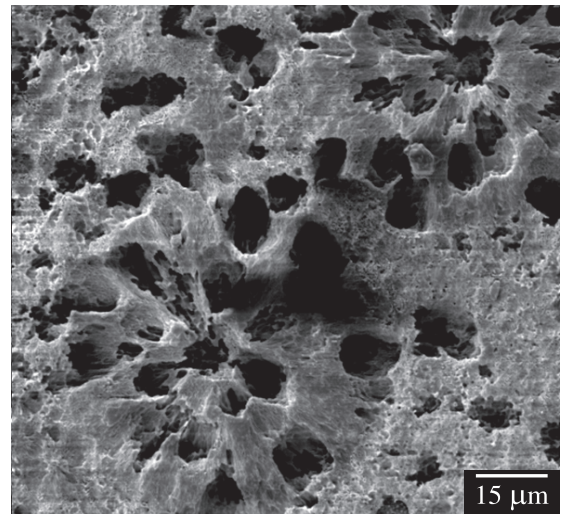

(c)

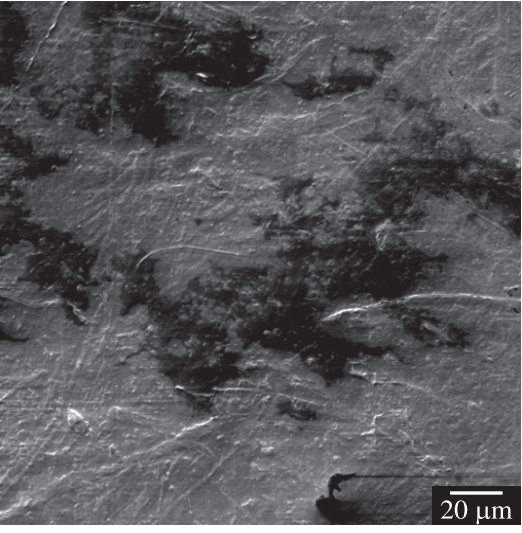

(c)

Figura 5. MEV de filmes de PP: a) filme original; b) biotratado em água do Rio Atibaia antes do descarte do efluente; c) biotratado em água do Rio Atibaia após o descarte do efluente.

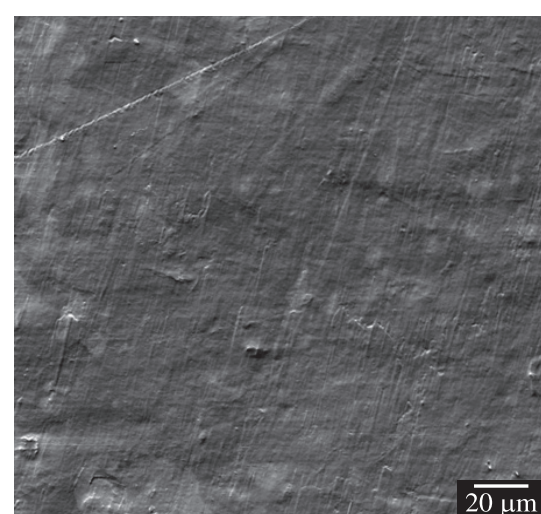

(a)

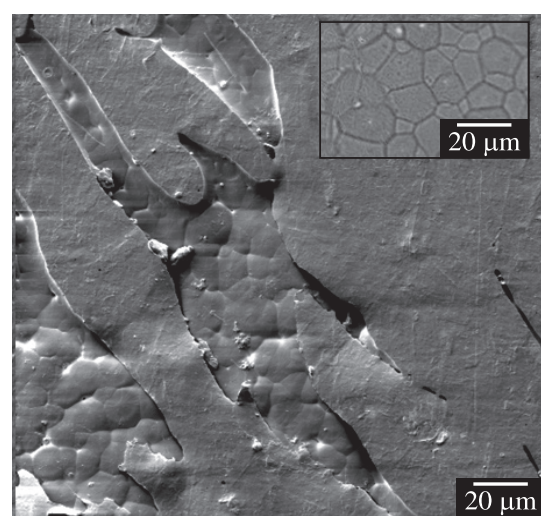

(b)

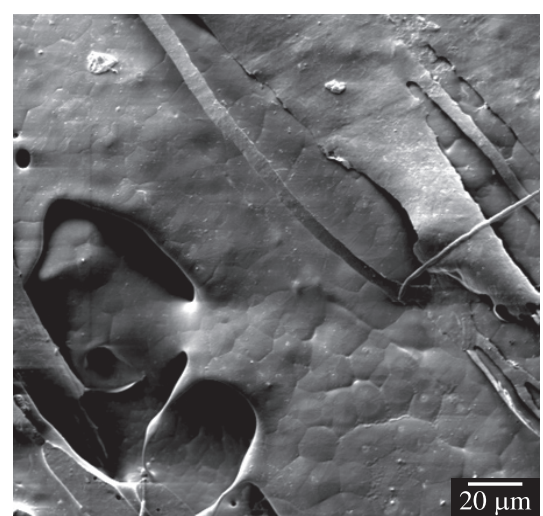

(c)

Figura 6. MEV de blendas de PP/PHB: a) filme original; b) biotratado em água do Rio Atibaia antes do descarte do efluente; c) biotratado em água do Rio Atibaia após o descarte do efluente. Em destaque: MO do PHB correspondente. 
resiste à umidade devido a suas propriedades hidrofóbicas o que dificulta o ataque enzimático, tornando-o resistente à decomposição por microrganismos no ambiente.

As micrografias ópticas (MO) e de varredura (MEV), antes e após os diferentes biotratamentos, foram importantes para a investigação da morfologia dos filmes. Na Figura 4a, referente à micrografia de $\mathrm{MEV}$ do filme original de $\mathrm{PHB}$, aparece uma superfície com marcas da prensa. Após o biotratamento do filme de PHB em água do Rio Atibaia antes e após o descarte do efluente da, observa-se uma estrutura porosa com furos, sugerindo degradação e remoção da camada com as marcas da prensa (Figura 4b, c). A alteração da superfície, devido à ação microbiana no filme intensifica a colonização do mesmo por microrganismos expondo o polímero ao contato com enzimas que agem sobre os carbonos dos grupos carbonila, os sítios característicos de ataque destas enzimas ${ }^{[18]}$.

A Figura 5a apresenta uma superfície de filme original de PP com marcas e riscos resultantes do processo de produção do filme. Os grânulos na superfície dos filmes biotratados (Figura 5b e d) podem ser de resíduos de biofilme que restaram após a lavagem dos mesmos, ou algum outro material aderido ou depositado durante o biotratamento. A estes grânulos não foi associado nenhum indício de biodegradação. A Figura $5 \mathrm{c}$ exibe um filme com manchas escuras em suas superfícies, que podem ser material oleoso depositado no filme, uma vez que o polipropileno é hidrofóbico e interage com hidrocarbonetos presentes na água do Rio Atibaia, após receber o efluente.

Torna-se difícil atribuir ao PP algum indício de biodegradação nos 120 dias de biotratamento, uma vez que sua hidrofobicidade dificulta a colonização de sua superfície por microrganismos, bem como o ataque enzimático. Por outro lado, o PP pode influenciar o processo de biodegração do PHB, modulando sua rápida degradabilidade.

As micrografias de MEV das blendas (Figura 6b, c), quando comparadas com o filme original (Figura 6a), revelam uma característica do processo de biodegradação, a descamação de camada por camada que é uma particularidade do $\mathrm{PHB}^{[3]}$.

$\mathrm{Na}$ Figura 6b, é possível visualizar uma primeira camada com sinais de degradação, provavelmente de PHB, mostrando formações regulares semelhantes às do homopolímero (no destaque da Figura 6b, obtidas por microscopia óptica). Na Figura 6c nota-se que outras camadas estão sendo expostas, além de furos e irregularidades observadas, sugerindo que a biodegradação ocorre por erosão superficial do filme, removendo camadas de PHB, das fases amorfa e cristalina, concordando com os resultados de FTIR.

\section{Conclusão}

Para o período de tempo estudado, a degradação dos filmes de PHB e da fração PHB das blendas de PP/PHB ocorre proporcionalmente nas fases amorfa e cristalina do PHB.

Os microrganismos presentes na água do Rio Atibaia mostraram-se capazes de biodegradar os filmes de PHB, bem como a fração de PHB presente na blenda, entretanto, o PP (homopolímero) e a fração PP na blenda permaneceram resistentes à ação microbiana. Verificou-se, ainda, que a degradação do PHB (homopolímero) e PHB presente na blenda foi mais intensa em água do rio à jusante (após receber o descarte do efluente), este fato pode estar associado à carga microbiana, que aumentou após o lançamento do efluente no rio.

$\mathrm{Na}$ blenda, a presença do PP dificulta o acesso dos microrganismos à fração de PHB, modulando (controlando), assim, a rápida degradação do $\mathrm{PHB}$.

Ambientes impactados como o Rio Atibaia são significativos na prospecção de microrganismos capazes de degradar uma vasta diversidade de moléculas.

\section{Agradecimentos}

Ao CNPq e ao NAP/MEPA/Esalq/USP, Piracicaba, SP.

\section{Referências Bibliográficas}

1. Wan, E.; Galembeck, E. \& Galembeck, F. - Quim. Nova na Escola, Edição especial, p.5 (2001)

2. Martins-Franchetti, S. M. \& Marconato, J. C. - Quim. Nova, 29, p.811 (2006).

3. Corrêa, M. C. S.; Rezende, M. L.; Rosa, D. S.; Agnelli, J. A. M. \& Nascente, P. A. P. - Polym. Test., 27, p.447 (2008).

4. Conti, D. S.; Yoshida, M. I.; Pezzin, S. H. \& Coelho, L. A. F. Fluid Phase Equi., 261, p.79 (2007).

5. Chandra, R. \& Rustgi, R. - Prog. Polym. Sci., 23, p.1273, (1998).

6. Arcana, I. M.; Sulaeman, A.; Pandiangan, K. D.; Handoko, A. \& Ledyastuti, M. -Polym. Int., 55, p.435 (2006).

7. Pelczar Jr., M. J.; Chan, E. C. S. \& Krieg, N. R. - "Microbiologia: Conceitos e Aplicações”, Makron Books, São Paulo (1997).

8. CETESB. "Relatório da qualidade das águas internas do Estado de São Paulo de 2001”, São Paulo (2002).

9. Flemming, H. C. - Polym. Degrad. Stabil., 59, p.309 (1998).

10. Spyros, A.; Kimmich, R.; Briese, B. H. \& Jendrossek, D. Macromol., 30, p.8218 (1997).

11. Sudhakar, M.; Trishul, A.; Doble, M.; Kumar, K. S.; Jahan, S. S.; Inbakandan, D.; Viduthalai, R. R.; Umadevi, V. R.; Murthy, P. S. \& Venkatesan, R. - Polym. Degrad. Stabil., 92, p.1743 (2007).

12. Atlas, R. M. - "Handbook of microbiological media", CRC Press, London (2004).

13. Shimao, M. - Cur. Op. Biotechenol., 12, p.242 (2001).

14. Bloembergen, S.; Holden, D. A.; Hamer, G. K.; Bluhm, T. L \& Marchessault, R. H. -Macromol., 19, p.2865 (1986).

15. Furukawa, T.; Sato, H.; Murakami, R.; Zhang, J.; Noda, I.; Ochiai, S. \& Ozaki, Y. - Polymer, 48, p.1749 (2007).

16. Xu, J.; Guo, B. H.; Yang, R.; Wu, Q.; Chen, G. Q. \& Zhang, Z. M. - Polymer, 43, p.6893 (2002).

17. Kansiz, M.; Dominguez-Vidal, A.; McNaughton, D. \& Lendl, B. - Anal. Bioanal. Chem., 388, p.1207 (2007).

18. Lucas, N.; Bienaime, C.; Belloy, C.; Queneudec, M.; Silvestre, F.; Nava-Saucedo, J. E. - Chemosphere, 73, p.429 (2008).

Enviado: 29/05/09

Reenviado: 01/02/10

Aceito: $02 / 02 / 10$

DOI: 10.1590/S0104-14282010005000024 